Recibido: 08-septiembre-2013

Aceptado: 20-septiembre-2013

\title{
SE CONFIGURA LA SEGUNDA SÍNTESIS DE LA TEORÍA
} EVOLUTIVA

\section{OSWALDO BÁEZ TOBAR}

Facultad de Ciencias Médicas

Universidad Central del Ecuador 


\section{RESUMEN}

La teoría evolutiva es la teoría fundamental de la biología. Se presentó a la comunidad científica en dos pequeños ensayos sobre la evolución por selección natural preparados en forma independiente por Charles Darwin y Alfred R. Wallace. Luego de la publicación del principal libro de Darwin: El Origen de las especies -que aporta numerosas pruebas y una amplia explicación de la teoría de la descendencia-, el pensamiento evolucionista fue denominado: darwinismo.

Con el avance de las ciencias de la vida a mediados del siglo XX se reformuló el darwinismo clásico en un nuevo corpus: la Teoría sintética de la evolución o neodarwinismo que se sustenta en la genética mendeliana y la genética de poblaciones; sobre esta base se construyó el pensamiento evolucionista moderno que tuvo vigencia plena en casi todo el siglo pasado.

Surgieron cuestionamientos en el seno del neodarwinismo que no pusieron en duda la validez de la teoría de evolución por selección natural, pero que llevaron a incorporan otros factores explicativos de la transformación evolutiva, además de la selección. En esa perspectiva se viene trabajando en las últimas décadas, al punto que se habla ya de una segunda síntesis de la teoría de evolución o Síntesis Expandida, que emerge del marco conceptual de la genética molecular, la genómica, la biología del desarrollo y la ecología; razón por la cual a este nuevo paradigma se lo conoce también como Eco-Evo-Devo.

Si la Teoría Sintética de la Evolución fue uno de avances mayores de las ciencias biológicas del siglo anterior, la segunda síntesis o Síntesis Expandida, se perfila como la construcción teórica más trascendental de la biología actual.

Palabras clave: evolución, teoría evolutiva, darwinismo, neodarwinismo, síntesis expandida.

\section{ABSTRACT}

Evolutionary theory is the fundamental theory of biology. It was presented to the scientific community in two small trials of evolution. The natural selection prepared independently by Charles Darwin and Alfred R. Wallace. After the publication of Darwin's main book: The Origin of Species, which provides numerous tests and a comprehensive explanation of the theory of descent - evolutionary thinking, it was called: Darwinism.

With the advancement of life sciences in the mid- twentieth century classical Darwinism is reformulated into a new body: the Synthetic Theory of Evolution or Neo-Darwinism that is based on Mendelian genetics and population genetics and on this basis was constructed modern evolutionary thought which took full effect in most of the last century. Questions arose within the neodarwinismo not questioning the validity of the theory of evolution by natural selection, but that led to incorporate other factors that explain the evolutionary transformation, besides to the selection. Under this perspective work has been done in recent decades to the point that now a second synthesis of the theory of evolution or Expanded Synthesis is talked, emerging from the conceptual framework of molecular genetics, genomics, developmental biology and ecology, giving a new paradigm known as Eco- Evo- Devo.

If the Synthetic Theory of Evolution was one of major advances in biological sciences from the previous century, the second synthesis or Expanded Synthesis is emerging as the most momentous theoretical construct of today's biology.

Keywords: evolution, evolutionary theory, Darwinism, Neo-Darwinism, expanded synthesis. 
La evolución biológica es uno de los principales atributos de los seres vivientes. Comprende transformaciones heredables de los organismos, cambios adaptativos a diferentes hábitats, modificaciones morfoanatómicas, fisiológicas y comportamentales, a la vez que la formación de nuevos tipos de organismos, nuevas especies y grupos superiores. Charles Darwin la definió como descendencia con modificación. Según Ernest Mayr (1978) la evolución biológica es el cambio en la diversidad y adaptación de las poblaciones de organismos. Para Theodosius Dobzhansky (1979) la evolución orgánica constituye una serie de transformaciones parciales o completas e irreversibles de la composición genética de las poblaciones. Consiste principalmente en radiaciones adaptativas a nuevos ambientes y el origen de nuevas formas de explotar hábitats ya existentes. Estos cambios adaptativos dan lugar ocasionalmente a una mayor complejidad en el patrón de desarrollo, de las reacciones fisiológicas y de las interacciones entre poblaciones y el ambiente. Estas y otras definiciones de evolución son aceptadas en la comunidad científica internacional.

La evolución de los seres vivientes fue objeto de investigación científica desde el siglo XIX y sigue siendo hasta el presente, lo que ha llevado a la construcción de un sólido pensamiento evolutivo y de una de las teorías más trascendentales de la ciencia moderna: la teoría evolutiva. Nació con la presentación de los esbozos de la teoría de evolución por selección natural - formulada independientemente por Charles Darwin y Alfred R. Wallace- y que fuera leída ante la Sociedad Linneana de Londres el 1 de julio de 1858, por lo cual la teoría debió ser llamada: Teoría Darwin-Wallace. Empero, Darwin ostenta la autoría principal de la teoría, porque logró estructurar un cuerpo teórico más consistente y sustentado en un mayor número de evidencias. A la naciente teoría se la denominó darwinismo, lo que fue reconocido por el propio Wallace. Quizá el aporte de Wallace no fue suficientemente valorado por mucho tiempo, pero en años recientes se están reexaminando las contribuciones de Wallace a la teoría de selección natural con nueva mirada. Gallardo (2013).

Darwin publicó el libro: El origen de las especies por selección natural el 24 de noviembre de 1859 , en él incluyó un amplio esquema aclaratorio con sus postulados y subteorías:

1. El mundo no es estático, sino que evoluciona, las especies cambian constantemente, se originan unas y se extinguen otras.

2. Las comunidades de seres vivos cambian con el tiempo: cuando más antiguas son, más diferenciadas se nos presentan con respecto a los organismos vivos del presente.

3. La evolución es gradual y continua, más no consiste en saltos discontinuos o cambios súbitos (estos postulados fueron coincidentes con los de Lamarck).

4. Los organismos semejantes están emparentados y descienden de un antepasado común (postulado de la continuidad de la descendencia).

5. La selección natural -principal subteoría y clave del sistema darwiniano- consta de dos premisas: variabilidad y selección con la subsecuente supervivencia y reproducción diferencial cuyos descendientes pasarían al siguiente ciclo de selección. 
Gracias a Darwin y su agudeza intelectual la evolución llegó a ser un hecho bien establecido y explicado por la teoría de la selección natural que se sustenta en las siguientes premisas. Variabilidad: los individuos que forman las especies presentan variaciones. Heredabilidad: algunas de las variaciones pasan a la descendencia. Superproducción: en cada generación se producen más descendientes de los que pueden sobrevivir. Competencia y reproducción diferencial: se expresa por la supervivencia y la reproducción de los individuos que poseen las variaciones más favorables, los cuales son seleccionados en la naturaleza.

Como consecuencia, las características de las poblaciones cambian de una generación a otra, por lo mismo la selección natural es un proceso que origina descendientes con modificaciones lo que se traduce con el tiempo en la evolución de los organismos. La evolución darwiniana es la transformación gradual por efecto de la selección natural sobre los individuos, las poblaciones y las especies.

La selección natural está estrechamente vinculada a la adaptación al ambiente debido a que aumenta la aptitud de ciertos individuos respecto de otros. La aptitud se traduce en eficacia darwiniana que es la habilidad de los organismos para sobrevivir y reproducirse en un ambiente determinado. De esta manera la selección natural se constituyó en el núcleo de la teoría evolutiva y uno los ejes de la biología.

La teoría de evolución se sustenta en una estructura lógica sencilla y en un modelo hipotético deductivo consistente $y$ en hechos demostrados y demostrables. Esta fue la gran tarea que impulsó Darwin desde su regreso del viaje en el Beagle en 1836; pues durante más de 20 años organizar las evidencias empíricas de la evolución que se reveló como un hecho natural, a la vez también trabajó en la construcción de la "teoría de las descendencia" como la llamaba.

La Teoría... y la publicación de El origen de las especies abrieron una nueva era en la historia intelectual de la humanidad. Con la teoría de evolución podían explicarse las adaptaciones y la diversidad de los organismos, el origen de las formas nuevas, muy organizadas e inclusive el origen del mismo hombre, mediante un proceso ordenado de cambios regidos por las leyes de la naturaleza. Darwin demostró que la diversidad de los seres vivos se podía explicar por procesos naturales. La teoría de evolución se convirtió en la teoría biológica más amplia, pues permite explicar -junto con la teoría mendeliana de la herenciamuchos fenómenos de los seres vivos: la diversificación de los organismos, el cambio gradual y las adaptaciones al ambiente.

\section{Del darwinismo clásico a la Teoría sintética de la evolución: visión histórica}

Por decenios el darwinismo mantuvo su estructura original sin sufrir cambios substanciales en el núcleo de su teoría, sin embargo, los aportes de las ciencias biológicas emergentes en especial de la genética mendeliana, la genética de poblaciones, la paleontología y la sistemática, contribuyeron a su enriquecimiento y desarrollo en la década de los 40 y 50, época en la cual se empezó configurar la teoría sintética de la evolución.

La teoría sintética o síntesis moderna de la evolución tomó forma en la década de los 50. Fue producto de una generación bri- 
llante de científicos encabezados por Theodosius Dobzhansky, Ernest Mayr, George G. Simpson y Sewall Wrigth quienes integraron los conocimientos de las ciencias biológicas alcanzados en la primera mitad del siglo XX; particularmente en los libros: Genética y origen de las especies, de Dobzhanzky; Sistemática y el origen de las especies, de Ernest Mayr; y Tiempo y modo en la evolución, de George G. Simpson.

En el congreso de Princeton realizado en 1947 se consagró la Síntesis Moderna de la Evolución con el aporte de las tres disciplinas mencionadas con la teoría de Darwin, por lo que se la denominó también neodarwinismo. Las premisas fundamentales del darwinismo original están presentes en la nueva síntesis: las pequeñas variaciones hereditarias originadas por las mutaciones, recombinaciones genéticas y otras; los caracteres adquiridos se destacan como la fuente de variación, pues esta obedece en gran medida a factores aleatorios; se ratifica en la idea central de que la selección natural actúa a favor de las variaciones más adaptables al medio, y que la evolución es un proceso continuo y gradual (Blanc, 1982).

En 1943 apareció la primera edición del libro: La evolución: síntesis moderna, de Julian Huxley. A esa época fue la obra más amplia y consistente del pensamiento darwinista con lo cual la síntesis moderna de la evolución pasó a ser la piedra angular y el principio unificador de la biología contemporánea. Sus seguidores creyeron tener en ella la respuesta a todos los procesos evolutivos. Se llegó a sostener: "El descubrimiento de los principios de la selección natural hizo comprensible la evolución; junto con los hallazgos de la genética moderna han hecho insostenible cualquier otro modelo de evolución" según la expresión de Huxley (ver Leith, 1986).

El neodarwinismo fue un principio unificador tan formidable que ningún académico respetable osó contradecirla, pues era una teoría convincente que de una plumada descifrada todo el problema de la evolución del mundo viviente. Pero está aparente seguridad de la teoría que todo puede explicar, fue su talón de Aquiles. El neodarwinismo fue ambicioso y en cierto modo también arrogante, afirmaron sus críticos.

Dado el carácter general del neodarwinismo se aplicó a todos los fenómenos evolutivos desde la microevolución hasta la macroevolución. Y se le dio ese carácter y esa amplitud, pero más tarde se advirtió la debilidad de la pretendida omnipotencia. En efecto, ese fue el núcleo de la incertidumbre que pronto debió afrontar el neodarwinismo (Leith, 1986). Por otra parte la discusión apuntó al cuestionamiento de poder real de la selección natural. ¿Es responsable de la adaptación evolutiva? ¿A qué nivel actúa la selección, sobre genes, individuos o sobre grupos? ¿Es capaz de crear nuevas especies?

\section{Análisis de la Teoría sintética de la evolución}

Ciertamente, después de varios años de estudios de los genetistas poblacionales que sustentaron fuertemente a la teoría sintética de la evolución se empezó a ver cierto desacoplamiento entre los modelos matemáticos aplicados a la evolución y la confrontación a la realidad natural de los seres vivos. Se empezó a poner en entredicho la validez de tales modelos, entre otras, por las siguientes razones: 
1. Por ser exagerados en sus pretensiones.

2. Porque en ciertos parámetros como aptitud (fitness) adaptación, selección y otros, no son mensurables.

3. Consideró a los genes en forma aislada, sin tomar en cuenta la interacción de estos en los genomas.

4. Al querer entender la especiación como simple cambio en la frecuencia de los genes en una población, se dio una explicación esquematizante y reduccionista.

En opinión de Gould (2004) la síntesis reduce a simple sustitución alélica (sustitución de genes) por selección en poblaciones, tanto la subespecialización, como la especialización, las tendencias (evolutivas) y fenómenos macroevolutivos. Era muy fácil -continua Gould- conocida la fase molecular de los genes, la mayoría de los biólogos evolucionistas llegaron a concebir todos los fenómenos evolutivos como meros cambios en las frecuencias génicas que serían seleccionadas posteriormente. La genética de poblaciones -que está en el corazón del neodarwinismo- se vio en una crisis de confianza respecto a su incapacidad de demostrar que la selección es una fuerza capaz de conducir realmente al "origen de las especies". El viejo edificio teórico erigido durante los días de la síntesis no concuerda con las observaciones en la naturaleza, todo lo cual llevó a concluir que la selección natural no puede explicar todo.

En el ámbito de la biología teórica se planteó otra discusión. Aceptar o no que los mecanismos básicos de evolución son extrapolables a cualquier nivel evolutivo, y que los procesos evolutivos son explicables en función de un solo mecanismo: selec- ción natural que actúa sobre la variabilidad de los organismos y que se transmite a la descendencia en poblaciones naturales.

Los paleontólogos (que tienen una visión espacio-temporal de la vida en la Tierra) consideran el fenómeno evolutivo que presenta el registro fósil, como el resultado de la acción de procesos y mecanismos distintos a aquellos que era considerados como básicos. Gould (2004) cuestionó a la síntesis moderna por haber adoptado una explicación monista de la evolución: selección de mutaciones al azar en poblaciones naturales; las que actuarían originando especiación y en períodos más largos serían la casusa de cambios evolutivos mayores, es decir: macroevolución.

En la década de los setenta se inicia una confrontación entre los evolucionistas: entre quienes sustentaban el monismo de la síntesis moderna y el adaptacionismo supuesto a todo cambio evolutivo, y los que los ponían en duda estas premisas. Otro punto de debate fue el dilema: evolución gradual versus evolución por saltos, es decir, la discusión entre gradualistas y saltacionistas. En contra del gradualismo sostenido por la síntesis moderna, se levantó el postulado de los paleontólogos Niles Eldredge y Stephen Jay Gould, de los equilibrios intermitentes "punctuated equilibria" o equilibrios puntuados. En esencia sostiene: no es verdad que una especie se transforme de modo gradual en otra (los fósiles no demuestran tal serie gradual de transformaciones), por el contrario: cada especie permanece estable con todos sus caracteres por varios millones de años, presentando cierta estasis morfológica; luego de ello es reemplazada bruscamente por otra distinta a la anterior. La estasis o equilibrio sería interrumpido episódicamente por fe- 
nómenos de especiación. Pero además de producirse la sustitución de una especie por otra en una localidad, la nueva especie procede de una de las inmigrantes, la mayoría de las cuales no sobreviven por largo tiempo sino, pues, una sola sobrevive. Además, dicha sustitución no es el producto de la microevolución, por lo mismo la especiación es un fenómeno distinto a la adaptación de las poblaciones por medio de selección (Eldredge, 1982, Gould, 2004).

La tesis de los equilibrios intermitentes despertó gran interés en el ámbito académico mundial, talvez por la vehemencia de quienes la sustentan o por la necesidad de innovar el neodarwinismo; y contribuyó al surgimiento de una corriente innovadora en el seno del neodarwinismo que estuvo representada por Richard Lewontin, H. Carson, G. Bush, M. J. D. White, S.M. Stanley y el propio Stephen Gould, quienes demostraron la insuficiencia de la síntesis -lo que no significa que consideraron inválida la teoría-, pero dieron un impulso al neodarwinismo ortodoxo y pugnaron por una visión más dinámica de la evolución; consideraron nuevos parámetros biológicos y ambientales como determinantes de los cambios evolutivos y reconocieron que en la formación de nuevas especies operan otros mecanismos además de la selección natural.

En efecto, se identificaron especiogénicos rápidos: especialización cuántica la especiación cromosómica, especiación por poliploidía; especiación por incompatibilidad del genoma (cambios en el ADN), especiación por reordenaciones secuenciales incompatibles en meiosis y especiación por reengarce genómico: reemplazo de unas familias multigénicas de acción reguladora por otras (Reig, 1983).

\section{Corriente innovadora de la Teoría sintética}

El conocimiento de los procesos especiogénicos, los avances en la biología del desarrollo y de la biología molecular obligó a reexaminar al neodarwinismo, en particular en sus aspectos más críticos. Los analistas más severos como los de Gould y Lewontin (que por cierto fueron neodarwinistas en su formación) buscaron modificar los principios básicos, aunque todavía se muestran reacios a abandonar la teoría mientras no exista otra que aporte una explicación más convincente. Biólogos de renombre publican artículos con títulos en verdad inquietantes: "¿Se necesita una buena síntesis de la evolución?" de Stebbins y Ayala. "En defensa del neodarwinismo" de Charleswopth, Lande, Slatkin. O ¿Está naciendo una nueva teoría general de la evolución?" de Stephen J. Gould (Leith, 1987).

Sobre un tema tan importante surgieron varias interrogantes: ¿Podrán los neodarwinistas salvar su teoría? ¿Estamos al borde de una nueva teoría general de la evolución? ¿Darwin ha caído en desgracia? ¿El ataque al neodarwinismo desde varios frentes (biológico y filosófico) acaso está orientado a combatir al evolucionismo? Lo cierto fue que el sorprendente progreso de la biología en los tiempos más recientes han llevado a concluir que la evolución entraña mucho más de aquello que sustentaba la moderna síntesis; y eso lo entienden los neodarwinistas contemporáneos, de ahí su posición más abierta. El neodarwinismo actual es más flexible que el de los años de la síntesis de la década de los 50 y 60; ya no rechaza los genes neutros, ni las tasas variables de evolución; ni la especialización brusca a través de los mecanismos cromosómicos y otras formas. En resumen, se 
admite la realidad compleja y multicausal de la evolución. Como los seres vivientes, la evolución es entendida y valorada en varios niveles: subespecíficos, específicos y supraespecíficos.

En el estadio subespecífico se analiza las poblaciones de organismos y se entiende a la selección actuando sobre la variabilidad para producir la adaptación al medio ambiente. Para este nivel hay numerosas pruebas experimentales que han permitido demostrar el efecto real de la selección natural.

El nivel específico aborda los procesos y mecanismos de formación de las especies. En este nivel la selección natural es el mecanismo implícito en la especiación alopátrica. Pero, muchos procesos asociados por la especiación como aislamiento geográfico, reordenamientos cromosómicos, poliploidías, secuencias repetidas de ADN, no tienen en la selección natural el mecanismo desencadenante, por lo que ésta no es explicación suficiente para la especiación.

El nivel supraespecífico (el de macroevolución) trata de procesos evolutivos a gran escala, como el surgimiento de taxones superiores: familias, órdenes... En este ámbito la selección natural se muestra más débil e insuficiente. La macroevolución está desacoplada de la microevolución, fue la advertencia de connotados biólogos.

Parecería que los neodarwinistas se dejaron deslumbrar por la elegancia y omnipresencia de su teoría, así como por la promesa de unidad de los primeros años, la que no llegaron a alcanzarla. Pero esto no significa que la síntesis neodarwiniana sea errónea, sino que la adhesión exclusiva al neodarwinismo impidió comprender la globabilidad de la evolución biológica. De ahí que en la propia matriz de la teoría sintética se impusieron varios esclarecimientos como los siguientes:

- Reexaminar las posibilidades de cambios morfológicos rápidos. (Se insistió en la gradación por mucho tiempo).

- Esclarecer el papel de los genes estructurales y reguladores, en especial de estos últimos que se hallan comprometidos alteraciones del ritmo de desarrollo, súbitas revoluciones genéticas, transferencias horizontales o "concertadas" de genes, redes génicas, interacción de los genes en el genoma... (Hechos que no estuvieron considerados en la síntesis por ser muy recientes).

- Superar el enfoque reduccionista, atomista de la naturaleza. La evolución abarca varios niveles jerárquicos en el mundo de lo viviente: desde las moléculas, a los organismos, poblaciones, comunidades... (El neodarwinismo aplicó las mismas reglas a todos).

- Reconocer que faltan todavía muchas piezas del rompecabezas de la evolución. ¿Cómo los genes forman los organismos? ¿Cómo inciden los procesos epigenéticos en el desarrollo? (Los nuevos conocimientos de la biología actual ayudarán a esclarecer varios problemas de la biología evolutiva, en especial de la macroevolución).

Gould (2004) resume el análisis contemporáneo de la síntesis moderna de la evolución en los siguientes términos: en las tres últimas décadas del siglo XX se produjeron 
descubrimientos científicos que exigieron replanteamientos teóricos, revisión principios y conceptos de la biología, lo cual tuvo efecto en el corpus de la teoría evolutiva; se introdujeron elementos adicionales que enriquecen la formulación darwiniana original, pero sin llegar a alterar el núcleo de la selección natural. Los cambios esenciales fueron en las siguientes direcciones:

1. La formulación de una teoría jerárquica de la selección natural (no solo organísmica) es decir que incluya otros niveles además de los individuos.

2. Restricción de la amplitud de la selección, lo que significa revisar la comprensión de la omnipresencia de la selección.

3. No a la extrapolación uniformista de los mecanismos filogenéticos microevolutivos.

4. Identifica a la especie como una individualidad darwiniana genuina y efectiva, es decir, como una entidad histórica discreta suceptible de selección. Esto permite superar la visión exclusivamete organísmica de la selección para incluir la teoría jerárquica de la selección natural, en la cual Gould reconocen varios niveles: gen, linaje celular, organismo deme, especie y clado. En este enfoque cabe la selección de especies que tiene el apoyo en testimonios fósiles y que concuerda con la teoría de los equilibrios puntuados de Gould y Eldredge.

\section{Revisión de la síntesis moderna de la evolución}

Todo lo expuesto en el acápite anterior llevó a la revisión de la síntesis moderna con- siderando los avances de la biología en las últimas décadas, especialmente en la biología del desarrollo, la citogenética, genética molecular, la ecología evolutiva... por lo que se prevé la ampliación y expansión de la teoría evolutiva.

\section{Contribuciones de la Biología del desarrollo}

Nuestras ideas sobre el gen y el carácter han sido revisadas detenidamente. El fenotipo es considerado cada vez más no como un mosaico de caracteres individuales controlados por los genes, sino la síntesis producto de un complejo sistema interaccionante, el epigenotipo total, Ernest Mayr (ver Waddington, 1976).

El fenotipo de los organismos es un fenómeno epigenético. En los procesos epigenéticos hay dos fundamentales: la morfogénesis y el carácter canalizado o amortiguado de las trayectorias epigenéticas (Waddington, 1976) La diversidad organísmica no se explica solamente por el complemento de los genes de un organismo sino por la forma que se usan esos genes en el desarrollo y por lo tanto en la expresión diferencial de dichos genes, lo que se conoce como epigénesis. La epigénesis es un fenómeno de regulación génica en cascada (Gallardo, 2011). Ahora se sabe que la expresión de los genes está regulada y dicha regulación ocurre durante el desarroIlo. (Pero, muchos de los defensores de la síntesis moderna consideraron que el desarrollo es algo irrelevante para explicar la evolución, pues creían que lo más importante es el cambio de frecuencia de genes en las poblaciones, lo cual extrapolado a todos los niveles del mundo biológico explicaba todo cambio evolutivo). 
La integración de la biología del desarrollo con la teoría evolutiva podría conducir a una ampliación y modificación importantes, sobre todo al ponerla en posibilidad de considerar en una forma más equilibrada el concurso de los factores externos e internos de la evolución; las contradicciones del desarrollo y su expresión morfológica (factores internos), la selección (factores externos al sistema en desarrollo) sólo sería efectivo en los estados descritos que a la vez comportarían su propia viabilidad (Maderson, citado en De Renzi, 1983).

La comprensión de la modularidad entendida como organización del cuerpo a base de módulos relativamente discretos y que pueden modificarse durante el desarrollo permite explicar de la diversificación morfológica, la formación de los patrones corporales, los fenómenos de alometría y heterocronía. La heterocronía es el cambio temporal del desarrollo de partes o regiones del cuerpo en una especie con relación al de sus ancestros (Gallardo, 2011).

Hasta la década del 80 en el ámbito de la biología evolutiva se aceptaba que la diversidad de formas vivientes obedecía a los cambios en los genes estructurales que constituyen un organismo a partir del cigoto. En opinión de Freeman \& Herron (2002) dos descubrimientos ayudaron a cambiar esta opinión: 1) Especies con fenotipos adultos tienen pocas diferencias genéticas; $y, 2) \quad$ Existen mecanismos genéticos y celulares similares que subyacen en el desarrollo de embriones donde los adultos son diferentes.

Cabe una pregunta: ¿Si los genomas y los procesos de desarrollo de los organismos muy diferentes son en gran parte los mismos, cuál es la causa de la diversidad morfológica que se observa en los seres vivien- tes? La explicación parece hallarse en los genes homeóticos que intervienen en la formación de patrones de diversidad lo que tendrían incidencia en la macroevolución. En efecto, muchos de los rasgos nuevos de los organismos pluricelulares surgen cuando tipos de células preexistentes aparecen en localizaciones nuevas o en momentos distintos en el embrión. Los organismos pluricelulares requieren de un sistema para ordenar a las células en un espacio tridimensional y para especificar el destino de dichas células. Las células deben identificarse para su localización, división, gastrulación, la simetría, segmentación, formación de cavidades corporales, diferenciación de los tejidos y órganos. Este es, por lo tanto, uno de los mecanismos de la evolución de la estructura y forma de las plantas y animales.

La genética del desarrollo reconoce en los animales dos tipos de genes homeóticos: loci HOM en los invertebrados, los loci HOX en vertebrados. En general se los conoce como loci HOX. Los genes homeóticos forman complejos de genes; guardan una perfecta correlación $3-5$ en el cromosoma y en la localización antero-posterior de los productos génicos en el embrión; cada locus del complejo tiene una secuencia de $180 \mathrm{pb}$ altamente conservada a la que se conoce como homeobox, homeocaja u homeosecuencias. Los productos de los genes homeóticos HOM y HOX son proteínas reguladoras que se unen al ADN y que controlan la transcripción de otros genes.

Un gen homeótico es un gen de control maestro que regula baterías de otros genes que en realidad crean la identidad anatómica de las partes del cuerpo. Los genes homeóticos dan instrucciones del desarrollo embrionario en una amplia variedad de 
organismos eucariontes. Con su presencia en diversos taxones los genes homeóticos permiten constatar la unidad en la diversidad de los seres vivos. (Mayr, 1998).

\section{Genes homeóticos y regulación de los pro- cesos ontogenéticos}

Los loci Hox regulan el destino de las células en el tiempo y en el espacio, es decir, el comienzo y fin del desarrollo embrionario $y$ el eje anteroposterior del cuerpo de un embrión, pues se encontró una correlación entre los genes homeóticos de los organismos y la complejidad morfológica. Los artópodos, por ejemplo, tienen la misma serie de loci homeóticos, pero estos se expresan en diferentes momentos y localizaciones; por lo cual, variaciones en la expresión de los loci homeóticos están correlacionadas con la variación en plan del cuerpo de los animales articulados, como los artrópodos y vertebrados, que incluye la diversidad apendicular y segmentación. La incidencia en la evolución radica en que las innovaciones morfológicas, como las que ocurren en los artrópodos por este mecanismo que a la vez generan modificaciones ecológico adaptativas en los animales (Freeman \& Herron, 2002). También se han identificado genes homeóticos en plantas angiospermas, en estas intervienen en la constitución de los verticilos florales. Se conoce ahora que la diversidad de formas en plantas y animales obedece a la diversidad evolutiva del número y de las interacciones de un pequeño número de genes que controlan la formación de patrones en el embrión (Campbell, et al., 2001).

A partir de la década de los ochenta se iniciaron estudios sostenidos de la biología evolutiva y biología del desarrollo: EvoDevo -como se conoce el nuevo enfoque (por las palabras en inglés Evolution y De- velopment)-, se basa en los estudios de la expresión génica a gran escala, mediante nuevas técnicas; lo cual ha permitido reconocer varios mecanismos de desarrollo evolutivo: heterocronía, duplicación y divergencia de los genes que asumen nuevas funciones, y co-opción que implica el uso de formas génicas preexistentes en nuevas tareas y estructuras. Las dos disciplinas: biología del desarrollo y biología evolutiva están dando nuevos frutos, quizá los más relevantes desde la nueva síntesis (Lindsay, 2003).

Cuando se formuló la síntesis moderna, la biología del desarrollo y la genética del desarrollo no eran aún ciencias establecidas, por lo que fueron excluidas de la síntesis moderna. (Quizá también porque se sobredimensionó a la genética de poblaciones como le mecanismo explicativo de la evolución; en tanto que la morfología y el desarrollo eran vistas como disciplinas que jugaban un papel pequeño en la teoría evolutiva moderna; a la vez que se entendía que la macroevolución se podía explicar por los mismos mecanismos de la microevolución).

En el ámbito de la biología evolutiva se llegó a plantear dos modelos explicativos: el de la genética de poblaciones que explica la selección de los organismos adultos que compiten por la ventaja reproductiva, y la genética del desarrollo que explica la filogenia y se basa en las semejanzas de los genes reguladores que son activos en los embriones y larvas. Todavía nos aproximamos a la evolución por los dos caminos. Ambos involucran descendencia con modificación y enfatizan en las semejanzas o diferencias entre los taxa (Gilbert, 2006).

La consolidación de la biología molecular del desarrollo como soporte de la biología 
del desarrollo permite ver claramente que a la síntesis moderna de evolución le faltaba algo, y que era insuficiente para explicar algunos hechos evolutivos, por lo que la inclusión del desarrollo en la explicación de la evolución dio un fuerte impulso a la nueva síntesis evolutiva que está naciendo.

\section{Contribuciones de la genética molecular}

La genética moderna ha dado un aporte substancial a la teoría evolutiva al conferir al genoma un papel más dinámico en los procesos de cambio, en oposición al darwinismo y neodarwinismo clásicos. Se sabe ahora que los genes no sufren pasivamente la evolución, sino que son entidades actuantes en su propia transformación. Basta citar algunas formas de acción genética: genes móviles (trasposones) que se intercalan en las secuencias de los cromosomas y transmiten información genética entre organismos y aún entre especies; genes profanos que detectan el ambiente y cambian su estructura; los supergenes cohesionados y estables; las familias multigénicas que codifican y regulan diversas especies de los fenotipos, y parecen actuar con cierta autonomía evolutiva; genes fuertemente epistáticos; genes reguladores de acción multifacética; genes autodinámicos y automuladores que codifican enzimas procesadoras de genes y que cambian su estructura en respuesta a las condiciones ambientales. $\mathrm{Y}$, genes experimentadores dotados de capacidad de transmitir a la línea germinal modificaciones inducidas por el fenotipo somático, según Reig (1983). El descubrimiento de la transcriptasa inversa que posibilita que un segmento del ARN provoque la síntesis de ADN. La aparición de variaciones enzimáticas (en el organismo) como consecuencia de variaciones ecológicas. Las "ecoproteínas" cuya síntesis parece ser inducida por cambios en el medio externo, entre otros.

Mucho de lo expuesto debilita el concepto unidireccional "descendente" implícito en el "dogma central": ADN, ARN, proteínas, y revela (en no pocos casos) un mecanismo feed-back o de retroalimentación y más aún la existencia de una vía ascendente de la información; lo que tendría enormes implicaciones en biología evolutiva; pues estaríamos de nuevo en el umbral del lamarckismo.

Cabe afirmara Reig (1983) "los sorprendentes avances de la nueva genética están revelando comportamientos evolutivamente activos de la organización genómica y poblacional de las especies; ello constituye un cambio conceptual drástico con respecto a la manera tradicional de concebir el proceso evolutivo en el contexto de la nueva síntesis".

En años recientes, el avance en el conocimiento de la evolución cromosómica, evolución genómica y evolución molecular están ejerciendo una fuerte influencia en los principios y conceptos de la evolución. La interpretación de la genómica comparada lleva a reconstruir filogenias y entender la unidad en la diversidad de los seres vivos, así como la complejidad estructural y funcional de los organismos (Gallardo (2011).

\section{Contribuciones de la Ecología}

La selección natural armoniza a los organismos con el ambiente físico y biótico en el que viven. La relación evolutiva entre el organismo y su ambiente aborda la ecología evolutiva. Los procesos evolutivos tienen una base genética y un componente ecológico: la evolución biológica es un pro- 
ceso ecogenético que implica transformación en el tiempo y diversificación en el espacio geográfico y ecológico. Los organismos forman parte de comunidades y ecosistemas marinos, dulceacuícolas o terrestres; la evolución ocurre en una infinidad de escenarios ecológicos donde viven comunidades ecológicamente interrelacionadas por competencia, depredación, simbiosis, parasitismo, mutualismo.... que se establecen por procesos evolutivos diversos, algunos de ellos se han establecido por coevolución (Ayala, Valentine, 1983).

El enfoque ecológico de la evolución lleva al análisis de la relación del organismo con el ambiente que subyace en los procesos de selección natural. Cabe remarcar que el ambiente es la suma de todos los factores físicos y biológicos que incide sobre los individuos, grupos familiares y poblaciones específicas que interactúan entre sí. La vida en la comunidad favorece procesos coevolutivos: evolución conjunta de dos o más taxones que tienen relaciones ecológicas estrechas en las cuales la evolución de uno de ellos depende de la evolución del otro, según Erlich y Raven (Pianka 1982). En la coevolución están inmersas muchas formas de interacción que producen modificaciones morfológicas y fisiológicas que tienen efecto en la supervivencia y evolución conjunta de organismos de especies diferentes.

Por mucho tiempo se pensó que el ambiente desempeña un papel poco importante en el desarrollo. Estudios recientes han revelado que el ambiente desempeña un papel significativo en el desarrollo de casi todas las especies, y que el genoma de plantas y animales ha evolucionado para para responder a las condiciones ambientales. Las relaciones simbióticas entre dos o más especies necesarias para el desarrollo completo de una o más de ellas; la plasticidad del desarrollo que depende de circunstancias ambientales hace posible la formación de diferentes fenotipos a partir de un mismo genotipo, que han sido denominados polifenismos; algunos polifenismos son provocados por señales ambientales (Gilbert 2006). Estos hechos ponen en evidencia la interacción entre los organismos y el ambiente no solo en el estado adulto sino también en etapas tempranas del desarrollo lo que a la vez incide en la evolución.

En síntesis, múltiples disciplinas de la biología actual están enriqueciendo el pensamiento lo permite vislumbrar una segunda síntesis evolutiva o teoría sintética de la evolución ampliada.

\section{¿Nace la segunda síntesis de la Teoría evolutiva?}

La traducción española de Evolution Development que se abrevia como Evo-Devo es la Biología Evolutiva del Desarrollo, una nueva disciplina emergente en las últimas décadas, que esclarece el papel de la ontogenia en la generación de novedades morfológicas y por lo mismo en la evolución; con lo cual ofrece renovador enfoque a la biología evolutiva (Muñoz-Chápuli, 2009). Según Gallardo (2011) el soporte teórico de la Evo-Devo se halla en la epigenética mas no en la genética de transmisión. Este enfoque que ha tomado mucho impulso en las últimas décadas viene desde Thomas $\mathrm{H}$. Morgan quien ya advirtió en la necesidad de diferenciar la transmisión hereditaria con el desarrollo embrionario que ocurre principalmente en el citoplasma, según Fox Keller, 2002, citado por Gallardo (2011). Con lo cual se insta a prestar atención a los procesos del desarrollo ontogenético. 
Por mucho tiempo se omitió la relación entre el desarrollo ontogenético y la evolución, pero después de décadas de distanciamiento se vio la necesidad de vincular las dos disciplinas biológicas en un nuevo enfoque que se ha revelado altamente positivo para la biología. El enfoque de la EvoDevo destaca la importancia de la epigénesis y los mecanismos de control que inciden en los cambios macroevolutivos, pues estos pueden ser explicados mejor desde el entendimiento de la acción de los genes que regulan el desarrollo ontogenético antes que por cambios en los genes estructurales.

Para la Evo-Devo los códigos epigenéticos constituyen una fuerza estructuralista sin parangón, al punto que ahora se afirma: "la ontogenia crea la filogenia" y con ello aportó nuevo vigor y amplió la comprensión sobre la formación de los organismos. La EvoDevo demostró que los organismos están organizados genéticamente por módulos discretos e interactuantes. Además la modularidad ha permitido comprender la diversificación de segmentos de cuerpo y las implicaciones macroevolutivas de la epigénesis Gallardo (2011).

Cabe precisar que los biólogos del desarrollo no ponen en duda el papel de la selección natural en la evolución. La Evo-Devo no refuta el neodarwinismo, sino que le completa y amplía. Difiere en la comprensión de los mecanismos del proceso evolutivo, pues asigna importancia preponderante al desarrollo ontogenético. La biología del desarrollo ha demostrado que la evolución se inicia al nivel organísmico individual y desde ese nivel emergen la novedades evolutivas. Por lo tanto, como afirma Gallardo (2011) a nivel individual se unifica la biología evolutiva con la biología del desarrollo, así nace la Evo-Devo. El avance en el conocimiento de la epigénesis y macroevolución... han socavado el viejo paradigma neodarwariniano al punto que se habla ahora de un nuevo paradigma evolutivo.

En la comunidad científica se ha producido una reevaluación de la teoría evolutiva y un remozamiento de la síntesis moderna en lo que se denomina síntesis expandida (Gould, 2004, Pigliucci, 2007). Esta nueva síntesis requiere un marco conceptual más amplio, puesto que la teoría actual está centrada en la transmisión de genes, pero se requiere una teoría de la forma para comprender cabalmente la evolución. La teoría expandida debería unificar la teoría de los genes y de las formas, de tal manera que contenga la visión Evo-Devo y una teoría más incluyente, que pueda acomodar los procesos epigenéticos y los no mendelianos. En esa integración se espera que la teoría de la complejidad desempeñe un papel importante, pues no supone linealidad. También requiere que se reevalúen los niveles de selección y se incluya a la ecología como parte de la explicación evolutiva; además de la información que está generando la genómica (Gallardo, 2011).

Por estas razones la síntesis expandida se la conceptualiza como: Eco-Evo-Devo, pues el ambiente se percibe como un agente normal en la producción de fenotipos (Gilbert, 2006). En este nuevo marco conceptual avanza la configuración de la teoría de la evolución revisada y expandida.

Si la síntesis moderna constituyó uno de los logros intelectuales mayores de las ciencias biológicas en el siglo anterior, la segunda síntesis se perfila como la construcción teórica más trascendental de la biología actual que lleve a la humanidad a una comprensión más amplia de la evolución. 


\section{BIBLIOGRAFÍA}

BLANC, M. (1982). Las teorías de la evolución, en Mundo Científico (La Recherche) 12:288-303

CAMPBELL, N. et al. (2001). Biología: conceptos y relaciones, 3a. Ed., México, Person Educación.

FREEMAN, S., HERRON, J.C. (2002). Análisis Evolutivo. 2a. ed. Madrid, Prentice Hall.

DE RENZI, M. (1983). "El neodarwinismo y las críticas impuestas a su reduccionismo radical por la paleontología y la biología del desarrollo", en Evolucionismo y cultura, Bilbao, España, ed. A. Dor. Ediciones Mensajero,.

ELDREDGE, N. (1982). La macroevolución, en Mundo científico (La Recherche) 16:972-803

GILBERT, S.F. (2006). Biología del desarroIlo, 7ạ.edición, Buenos Aires, Argentina. Editorial Médica Panamericana.

GALLARDO, M. (2011). Evolución: el curso de la vida, Buenos Aires, Editorial Médica Panamericana.

GALLARDO, M. (2013). Alfred Russel Wallace: obra y figura. Revista Chilena de Historia Natural 86:214-250.

GOULD, S. J. (2004). Estructura de la Teoría de la Evolución, Barcelona, Tusquets Editores S.A.
LEIGTH, B. (1986). El legado de Darwin, Barcelona, España, Salvat Editores.

LINDSAY, S. (2003). Develompmental Evolution. Enciclopedia del Genoma Humano. Macmilan Publishers Ltd. Nature Publishing Group. www.ehgonline.net

MAYR, E. (1978). La Evolución, en Investigación y Ciencia (Scientific American) 26:2-16.

MAYR, E. (1998). Así es la biología, Madrid, Editorial Debate, S. A.

MUÑOZ-CHÁPULI, R. (2009). Evo-Devo: Hacia un nuevo paradigma en biología evolutiva.

http://www.encuentros.uma.es/en cuentros100/evodevo.htm. 16/03/2009.

REIG, O. (1983). "Teoría de la Especiación Animal", en IX Congreso Latinoamericano de Zoología, Informe final. Ed. Pedro Aguilar. Arequipa, Perú.

RUFFIÉE, I. (1983). De la biología a la cultura. Barcelona España, Muchnik. Editores S.A.

WADDINGTON, C. H. et al. (1976). Hacia una biología teórica, Madrid España, Ed. Alianza. S.A. 